\title{
TRUTH, MEANING, AND CIRCULARITY
}

\begin{abstract}
It is often argued that the combination of deflationism about truth and the truth-conditional theory of meaning is impossible for reasons of circularity. I distinguish, and reject, two strains of circularity argument. Arguments of the first strain hold that the combination has a circular account of the order in which one comes to know the meaning of a sentence and comes to know its truth condition. I show that these arguments fail to identify any circularity. Arguments of the second strain hold that the combination has a circular explanation of the ideas or concepts of meaning and truth. I show that these arguments identify a genuine, but acceptable, circularity.
\end{abstract}

\section{INTRODUCTION}

For almost forty years there was general agreement with Dummett's (1959) thesis that the deflationary view of truth cannot successfully be combined with the truth-conditional theory of meaning. While the consensus was disrupted with the dissent of Lance (1997), Williams (1999), and Kölbel (2001, 2002), proponents of the thesis still nourish a small family of arguments in its favor. ${ }^{1}$ My topic is one remarkably resilient variety of argument, that the combination of deflationism and the truth-conditional theory of meaning is impossible for reasons of circularity. I will show that arguments of this heirloom variety do not work.

Hereafter, I will use 'Combination' as shorthand for 'the combination of the deflationary view of truth and the truthconditional theory of meaning', and the name 'Immiscibility' for the thesis that the deflationary view of truth cannot successfully be combined with the truth-conditional theory of meaning. The theory of meaning I have in mind is Davidson's.

The circularity arguments can be distinguished from other arguments for Immiscibility by an emphasis on what is prior 
in the order of understanding; they hold that Combination proposes an unacceptably circular order of understanding of truth and meaning. Circularity arguments are notable for their tenacity in the literature, with the earliest example in Dummett (1959), and recent examples in Brandom (1994, 1997, 2002), Collins (2002), Dummett (1999, 2002, 2003), and Gupta (1993). But in addition to circularity arguments, there are two other varieties of argument for Immiscibility, explanatory inadequacy arguments, like those of Davidson (1990), Etchemendy (1988), Horwich (1998), Patterson (2005), Rumfitt (1995), and Soames (1997, 1999), and modal confusion arguments, like that of Soames (1984). Explanatory inadequacy arguments hold that Combination leaves important aspects of meaning unexplained. ${ }^{2}$ Modal confusion arguments hold that Combination is incoherent because the two theories involved have contradictory views about the modal status of the $\mathrm{T}$-sentences which are at the heart of the truth-conditional theory of meaning and of some varieties of deflationism. ${ }^{3}$ Thus modal confusion arguments aim to establish Immiscibility by way of defense of a stronger thesis, Incompatibility, where Incompatibility is the thesis that the deflationary view of truth and the truth-conditional theory of meaning are incompatible, strictly speaking - i.e., that Combination contains a contradiction. This paper deals only with circularity arguments for Immiscibility, leaving aside discussion of modal confusion and explanatory inadequacy arguments.

The circularity arguments share the view that Combination has a circular account of which comes first, truth or meaning, and for this reason I will call them Chicken-and-Egg arguments, but they are not homogenous. There are two distinct strains: The Interpretive Chicken-and-Egg arguments charge Combination with circularity in the order in which we come to know the meaning of a sentence $P$ and come to know its truthconditions, whereas the Explanatory Chicken-and-Egg arguments charge Combination with circularity in the order in which we explain the ideas or concepts of meaning and truth. (The Explanatory Chicken-and-Eggs are thus hybrid arguments, combining an explanatory inadequacy argument with a 
circularity argument.) I describe Interpretive Chicken-and-Eggs more fully in section 4 and Explanatory Chicken-and-Eggs in section 6. I advocate the elimination of circularity arguments; I reject Interpretive Chicken-and-Eggs in section 5 and Explanatory Chicken-and-Eggs in section 7. I show that Interpretive Chicken-and-Eggs fail to identify any circularity in Combination, whereas Explanatory Chicken-and-Eggs identify a genuine, but acceptable, circularity. I begin with a note about deflationism in section 2 and a brief description of Davidson's theory of meaning in section 3.

\section{DEFLATIONISM}

Throughout the paper I assume familiarity with deflationism about truth. I use 'deflationism' as an umbrella term covering those theories of truth that deny that the truth predicate's function is to attribute a rich, substantial, property of truth to a sentence or proposition. Where I speak of the redundancy theory, disquotationalism, minimalism, or the anaphoric theory, I have specific deflationary theories in mind, those stemming from Ramsey, Quine, Horwich, and Brandom, respectively. I will introduce very few details, focusing on the positive account of the truth predicate.

Ramsey's redundancy theory holds that "It is true that Caesar was murdered' means no more than that Caesar was murdered ... ['It is true that' is a phrase] which we sometimes use for emphasis or for stylistic reasons, or to indicate the position occupied by the statement in our argument." (1931, p.106). Quine's (1970) disquotationalism holds that the truth predicate has expressive and logical functions. A truth ascription like "George is extravagant" is true' is an indirect way of saying something about the world, that George is extravagant. Universally quantified truth ascriptions abbreviate infinite conjunctions, and existentially quantified ascriptions abbreviate infinite disjunctions. For example, for 'Everything George says is true', each conjunct has the form 'If George says "s", then s'. Horwich's (1998) minimalism holds that the 
truth predicate allows us to capture certain generalizations, for example generalizing from 'If Alice sings then Alice sings' to "Every statement of the form "If $p$ then p" is true', and allows us to express commitment to propositions that we cannot access, as in 'What Alice believes is true'. Brandom's (1994) anaphoric theory acknowledges debts to Grover et al.'s (1975) prosententialism. It holds that locutions such as ' $\ldots$ is true' are prosentence-forming operators. Where a noun phrase precedes '... is true' to form a prosentence, the noun phrase determines an anaphoric antecedent, and the content of the prosentence is inherited from that antecedent.

\section{THE TRUTH-CONDITIONAL THEORY OF MEANING}

My current project concerns the compatibility of the truthconditional theory of meaning with deflationism, not its merits, so I will describe but not defend the theory of meaning in question. Two aspects of Davidson's theory are immediately relevant to my argument - the way in which the theory seeks to explain meaning itself, and the way in which the theory tells us we may come to know the meaning of a sentence. The former bears on Explanatory Chicken-and-Egg arguments, the latter on Interpretive Chicken-and-Egg arguments.

Davidson supposes (for reasons that we will not delve into here) that the concept of meaning is an intractable subject for conceptual analysis, and that the problem of understanding the concept of meaning, and thus of explaining meaning, should be approached obliquely. ${ }^{4}$ On this approach, the theorist sets out to consider what would be required to develop a meaning theory for a particular language, where a meaning theory for a language $\mathrm{L}$ is a theory that allows interpretation of all the sentences of L. (A meaning theory is not a theory of meaning.) Consideration of how to accomplish this practical task is intended to illuminate the concept of meaning, without any direct analysis. The idea is that knowing how to construct a meaning theory would tell us everything we want to know about meaning, and thus provide a theory of meaning. 
Adoption of the theory-building approach leaves open the method by which a meaning theory should be constructed. Davidson proposes that a truth theory for $\mathrm{L}$ can serve to give the meanings of sentences of $\mathrm{L} .{ }^{5} \mathrm{~A}$ truth theory for $\mathrm{L}$ will entail instances of the schema

\section{(T) $s$ is true-in-L if and only if $p$}

where $s$ is replaced by a structural description of a sentence of $\mathrm{L}$ and $p$ by a sentence of the metalanguage. Davidson argues that if the truth theory has been constructed in the right way, then each theorem of form (T) derived in accordance with certain constraints gives an interpretation of the sentence that replaces $s$ by specifying the conditions under which the sentence is true. ${ }^{6}$ Each of these properly derived T-theorems should replace $p$ by a good translation of $s$. Call such instances of (T) T-sentences. For example, if

'Tá féar glas' is true-in-Irish if and only if grass is green

is a T-sentence for Irish, 'Tá féar glas' means that grass is green. If we understand the T-sentence (i.e., understand the metalanguage of the truth theory), and we know the right things about it - e.g., that it is a T-theorem that has been derived in the right way - then we know what 'Tá féar glas' means. This commits Davidsonians to a claim that will play a central role in my discussion of Interpretive Chicken-and-Egg arguments. Where the proper conditions are met:

(1) Knowing the truth-conditions of some sentence $P$ is sufficient for knowing $P$ 's meaning.

The meaning theory for $\mathrm{L}$ (i.e., the theory that allows interpretation of sentences of L) consists of the truth theory plus the information required to allow use of the truth theory for interpretation (e.g., that the truth theory has been properly constructed).

A meaning theory is not yet a theory of meaning; the meaning theory tells us about meanings, but not about meaning. A theory-builder's theory of meaning will describe the 
method by which a meaning theory is constructed, and will make explicit the insights into meaning that have been gleaned by considering how best to construct a meaning theory. For example, if Davidson has got things right so far, the thesis of the indeterminacy of interpretation and the rejection of the analytic/synthetic distinction will have their place in the theory of meaning.

Advocates and critics of the theory-building approach often say that consideration of the method of constructing a meaning theory will illuminate meaning, or lay bare the workings of the language. ${ }^{7}$ The illumination metaphor is poorly fleshed out by Davidsonians, but the idea is that the theory tells us something substantial about what meaning is by outlining the connections between the concept of meaning and other concepts. The way in which illumination is meant to take place is indicated by Davidson (1973, 1990, 1996). The meaning of a sentence, in concert with the speaker's beliefs, desires, and intentions, results in verbal behavior. Meaning, belief, desire, and intention are unobservable; we are to gain an understanding of the concepts of meaning et al. and their application to speakers by observing what is accessible speech - and learning how it might be interpreted. The later Davidson makes it clear that truth is one of the things to be illuminated in this way. The plan is to arrive at an understanding of meaning, truth, and the rest by showing how to mold a truth theory for $\mathrm{L}$ to speaker behavior. There will be no reduction of meaning to anything else; meaning will be illuminated by drawing out the connections between the concept of meaning and other concepts. The latter part of Davidson's project remains incomplete - the connections between the concepts of meaning, belief, desire, intention, truth, and whatever else is required, have not been fully delineated, and cannot be fully delineated until the method by which a meaning theory is constructed has been settled. ${ }^{8}$

Davidson (1973, 1990) argues that if the illumination of meaning is to be successful, the evidence for a truth theory for L cannot "assume in advance the concepts to be illuminated" (1990, p. 314). Partly for this reason, he proposes that we con- 
sider what would be required for radical interpretation - interpretation of a speaker where the interpreter and the observed speaker have no shared language. For full illumination,

the evidence must be of a sort that would be available to someone who does not already know how to interpret utterances the theory is designed to cover: it must be evidence that can be stated without essential use of such linguistic concepts as meaning, interpretation, synonymy, and the like. (Davidson, 1973, p. 128)

Given Davidson's admonition that the radical interpreter's evidence cannot assume the concepts to be illuminated, one way to show Immiscibility for reasons of circularity would be to show that, for Combination, the radical interpreter's evidence is so tainted. However, there is no reason to suppose that the evidence is suspect in this way, and to date Circularity arguments have not taken this tack. The crucial evidence for the radical interpreter is that a speaker holds a sentence true. Holding true is an easily recognized, coarse-grained proattitude towards a sentence. Recognizing that a speaker holds a sentence true allows the radical interpreter to propose an instance of $(\mathrm{T})$ as a tentative candidate for a $\mathrm{T}$-sentence for the speaker. The radical interpreter's evidence that someone holds something true is behavioral evidence, perfectly free of the concepts to be illuminated. Certainly the interpreted speaker's verbal behavior is influenced by what she takes to be true and what she takes sentences to mean; these facts make interpretation based on behavior a worthwhile exercise, but do not indicate that the radical interpreter's evidence itself assumes the concepts to be illuminated. The appearance of the word 'true' in the phrase 'holding true' should not mislead. To judge that a speaker holds a sentence true is to code a speaker's behavior. Judgments like this are part of the radical interpreter's technique. While the evidence for the interpreter's truth theory must be free of the concepts to be illuminated, Davidson offers no reason to suppose that the radical interpreter's methods must be equally innocent.

There are some clear limits on the deflationary theories that might be combined with the truth-conditional theory of 
meaning. First, the meaning theory must meet Davidson's goal of explaining compositionality, presumably by way of incorporating a compositional truth theory. So a deflationism that forms part of Combination must permit a Tarski-style recursive definition of 'true-in-L', thereby allowing the derivation of $\mathrm{T}$-sentences as theorems from axioms that specify values for subsentential expressions of L. Deflationary theories that obviously meet this requirement are described by Leeds (1978) and David (1994). Depending on the details, some overtly non-recursive deflationary theories might be pressed into service as well. For example, a deflationary theory that treats certain true instances of $(\mathrm{T})$ as partial definitions of truth may suffice, provided that a recursive definition of 'truein- $L$ ' is permitted after the fact, i.e., not as a primary definition of truth, but in addition to a primary definition. However, a deflationary theory that allows no recursive definition of 'true-in-L' will not do for Combination. Second, since by definition a radical interpreter and her observed speaker begin with no shared language, deflationary theories that cannot accommodate truth attributions to sentences one does not understand are ruled out. Thus Resnik's (1990) immanent truth, which does not permit an attribution of truth to a sentence of a language other than one's own, and Field's (1994) pure disquotationalism, which does not permit attribution of truth to a sentence not in one's own idiolect, could not form part of Combination. But while it is clear that not just any deflationary theory can form part of Combination, the limits just discussed do not rule out Combination entirely. The question I will address is whether Combination is doomed by the circularity arguments.

We are now ready to turn our attention to the first strain of circularity argument, the Interpretive Chicken-and-Egg.

\section{INTERPRETIVE CHICKEN-AND-EGG ARGUMENTS}

Interpretive Chicken-and-Egg arguments hold that Combination describes a circle in the order in which we come to know 
the meaning of a sentence $P$ and come to know a statement of its truth-conditions. Dummett provides the locus classicus for Chicken-and-Egg arguments (of all kinds) in his assessment of the redundancy theory of truth.

[If] we accept the redundancy theory... we must abandon the idea which we naturally have that the notions of truth and falsity play an essential rôle in any account either of the meaning of statements in general or of the meaning of a particular statement. ...[In] order that someone should gain from the explanation that $P$ is true in such-and-such circumstances an understanding of the sense of $P$, he must already know what it means to say of $P$ that it is true. If when he enquires into this he is told that the only explanation is that to say that $P$ is true is the same as to assert $P$, it will follow that in order to understand what is meant by saying that $P$ is true, he must already know the sense of asserting $P$, which was precisely what was supposed to be being explained to him. (Dummett, 1959, p. 7) ${ }^{9}$

Dummett tells us in the passage that the redundancy theory forces the abandonment of two ideas - that the notions of truth and falsity play an essential role in any account of the meaning of statements in general or of the meaning of a particular statement. However, the argument as stated does not show that the redundancy theory forces abandonment of either of those ideas. Nor does it directly address claim

(1) Knowing the truth-conditions of some sentence $P$ is sufficient for knowing $P$ 's meaning.

Rather, it shows at best that with the redundancy theory, we must abandon the distinct idea:

(2) we can come to know the meaning (sense) of a sentence $P$ by previously coming to know the truthconditions of $P .^{10}$

Dummett believes (2) is entailed by (1); if the hapless student is to "gain from the explanation that $P$ is true in suchand-such circumstances an understanding of the sense of $P$, he must already know what it means to say of $P$ that it is true" (emphasis mine).

The redundancy theory tells us that "to say that $P$ is true is the same as to assert $P$." So, to understand "what it means 
to say of $P$ that it is true" (and thus to understand what it is for $P$ to be "true in such-and-such circumstances") we must understand what it is to assert $P$. To understand what it is to assert $P$, we must know $P$ 's meaning (sense). In short, the redundancy theory is committed to:

(3) We must know P's meaning in order to know the truth-conditions of $P$.

As Dummett sees it, (3) tells us that we must "already know the sense of asserting $P$ " to know the truth-conditions of $P$ (emphasis mine). So he believes that (3) entails:

(4) We can come to know the truth-conditions of $P$ only if we have previously come to know the meaning of $P$.

From (2) and (4), it follows that

(5) We can come to know the meaning of a sentence $P$ by previously coming to know the truth-conditions of $P$ only if we have previously come to know the meaning of $P$.

But it is circular to suppose that we can come to know the meaning of a sentence only if we have previously come to know the meaning of the very same sentence. Since (5) follows from (2) and (4), Combination is circular, and must be rejected.

Dummett continues to embrace his 1959 argument. We find similar arguments, with Davidson firmly in mind, in Dummett (1999) with regard to minimalism, (2002) with regard to both disquotationalism and minimalism, ${ }^{11}$ and (2003) with regard to deflationism defined to include Horwich's minimalism, McGrath's weak deflationism, and disquotationalism. ${ }^{12}$ Each argument accuses Combination of circularity, sometimes explicitly, sometimes implicitly. With regard to a number of deflationary theories broadly understood, we are told that Combination is "grossly circular ..." (2003, p. 24), and where minimalism is concerned, that Combination is "caught in a vicious circle" (2002, p. 252); with regard to 
disquotationalism, we are told that it is "impotent to characterize a notion of truth capable of serving as a theoretical notion within a theory of meaning" (2002, p. 256). All the arguments use (4) as a premise. ${ }^{13}$ The use of (2) as a premise is explicit in Dummett (1999), but not in Dummett (2002) or (2003), where the explicit commitment of Davidsonians is rendered more along the lines of (1). However, (5) does not follow from (4) without (2), so Dummett must assume either that (1) implies (2), or that (2) is an independent commitment of the truth-conditional theory of meaning.

Gupta (1993) also considers an Interpretive Chicken-andEgg, this one for a T-biconditional-based form of deflationism, e.g., some versions of disquotationalism. Gupta's variant requires that deflationism be committed to the claim that the meaning of 'true' is given by instances of (T). (Gupta argues that deflationism ought not be committed to that claim, and hence does not endorse Immiscibility on the grounds of the Chicken-and-Egg he describes.) The claim "suggests the following picture of our acquisition of 'true': We first learn some first-order words ('snow,' 'white,' etc.) and then we arrive at 'true' definitionally through the T-biconditionals." (Gupta, 1993, p. 69). Thus deflationism is committed to (4); "our understanding of 'true,' according to the picture, rests on our prior understanding of "snow is white"، (1993, p. 69, emphasis mine). Gupta concludes: "Given this picture, it follows immediately that we cannot explain our understanding of "snow is white' in terms of our understanding of 'true."' (1993, p. 69) i.e., we cannot accept (1). The purported Davidsonian commitment to (2) is implicit. But if the conclusion is that Combination is circular, (2) is required to generate the circularity. ${ }^{14}$

\section{WHY INTERPRETIVE CHICKEN-AND-EGG ARGUMENTS DO NOT WORK}

The reader may have sensed my skepticism regarding (2) and (4). I will argue that the Interpretive Chicken-and-Egg arguments do not demonstrate Immiscibility, on the grounds that Combination is not committed to either (2) or (4). First, I 
argue that (1) does not imply (2), and that Davidsonians are not independently committed to (2). Then I argue that (3) does not imply (4), and that deflationists are not independently committed to (4).

Claim (1) has the form 'knowing $\mathrm{q}$ is sufficient for knowing p'. The proponent of the Interpretive Chicken-and-Egg wrongly assumes that if knowing $\mathrm{q}$ is sufficient for knowing $\mathrm{p}$, then it ought to be possible to know $\mathrm{q}$ independently of knowing $\mathrm{p}$, so that it ought to be possible to know q prior to knowing $\mathrm{p}$. But consider cases where $\mathrm{p}$ is a constituent of $\mathrm{q}$; suppose that $\mathrm{q}$ is 'Alice and Mike are going to the party' and $\mathrm{p}$ is 'Alice is going to the party'. In cases like this, knowing $\mathrm{q}$ is sufficient for knowing p, but I could not know q independently of, or prior to, knowing p. Further, consider cases where $\mathrm{p}$ and $\mathrm{q}$ are related in such a way that to know $\mathrm{q}$ is to know p; again, while knowing $\mathrm{q}$ is sufficient for knowing $\mathrm{p}$, I could not know q independently of, or prior to, knowing $\mathrm{p}$. For example, suppose that $\mathrm{q}$ is ' $\mathrm{Jim}$ is a bachelor' and $\mathrm{p}$ is 'Jim is an unmarried man', or (more controversially, depending on one's views on other philosophical matters) that $\mathrm{q}$ is 'the present Queen of England is married' and p is 'Elizabeth Windsor is married'. In these cases, getting to know $\mathrm{q}$ is a way of getting to know p, but I cannot get to know q before getting to know p. Since 'knowing q is sufficient for knowing p' does not imply 'we can come to know p by previously coming to know q', (1) does not imply (2).

Claim (1), as you will recall, tells us that knowing the truth-conditions of some sentence $P$ is sufficient for knowing $P$ 's meaning. On Davidson's view, this is a case where $\mathrm{p}$ and $\mathrm{q}$ are the same, so that (under the right conditions) to know $\mathrm{q}$ is to know p. It should not be possible to know q first, and then learn p. So it should not be possible to know the truthconditions of $P$ prior to, or independently of, knowing $P$ 's meaning. But this raises a question: How can we get to know $P$ 's meaning by getting to know $P$ 's truth-conditions, if not by getting to know $P$ 's truth-conditions first, i.e., if not in the order specified by (2)? 
While a Davidsonian theory of meaning describes what would be sufficient for interpretation, it does not describe what ordinary speakers use for interpretation. ${ }^{15}$

Kurt utters the words 'Es regnet' and under the right conditions we know that he has said that it is raining. Having identified his utterance as intentional and linguistic, we are able to go on to interpret his words.... What could we know that would enable us to do this? How could we come to know it? The first of these questions is not the same as the question what we do know that enables us to interpret the words of others.... The second question, how we could come to have knowledge that would serve to yield interpretations, does not ... concern the actual history of language acquisition. It is thus a doubly hypothetical question: given a theory that would make interpretation possible, what evidence plausibly available to a potential interpreter would support the theory to a reasonable degree? (1973, p. 125)

Davidson's answer to the first question - what could we know that would allow interpretation of an utterance? - is given by claim (1); under the right conditions, knowing the truth-conditions of the utterance would be sufficient. The answer to the second question - how could we come to know whatever it is that allows interpretation of an utterance? will tell us in what order the knowledge is acquired, thus confirming or denying claim (2). But the second question is "doubly hypothetical"; his question does not "concern the actual history of language acquisition", rather, it concerns the fictional history of the radical interpreter (1973, p. 125).

Since the radical interpreter's fictional doings inform the answer to Davidson's second question, in answering it we must consider what happens as the interpreter comes to know the meanings of sentences. Crucially, he does not first come to believe the T-sentences he develops and then succeed in interpreting the sentences of the language. Rather, he interprets as he goes - giving tentative interpretations, and thus instances of $(\mathrm{T})$; proposing tentative axioms for the truth theory; generating new $\mathrm{T}$-theorems and testing them; revising existing interpretations and existing instances of (T). The first interpretations are more than likely poor ones, the last interpretations good ones, so that the last instances of $(\mathrm{T})$ are 
T-sentences. His procedure has similarities to that dismissed as circular by Chicken-and-Egg arguments. He generates an instance of (T) for $P$, because he believes $P$ is to be interpreted in a certain way; he tests to see whether his instance of (T) fits the evidence; he comes to a new belief about $P$ 's interpretation and its truth-condition, and so on. Once the interpretation is sufficiently well justified, his beliefs about $P$ 's meaning alchemize into knowledge about $P$ 's meaning, and his beliefs about the proper T-sentence for $P$ alchemize into knowledge about $P$ 's truth-conditions. The transmutation happens all at once - neither comes first. Davidsonians can hold that knowledge of the truth-conditions of $P$ suffices for its interpretation, without holding that the radical interpreter comes to know $P$ 's meaning by first coming to know its truth-condition. He comes to know both at once. Thus Davidson, and thereby Combination, does not hold claim (2).

It does not immediately follow that there is nothing to fear from the Interpretive Chicken-and-Egg arguments. Without (2), Gupta and Dummett cannot derive (5). However, Gupta and Dummett argue that on a deflationist view, one must know the meaning of a sentence before knowing its truth-conditions; hence they might argue that even if Davidson is not committed to (2), Immiscibility holds because deflationism's commitment to (4) means that deflationism cannot allow that we come to know a sentence's meaning and its truth-condition simultaneously. But this line of objection is easily dismissed.

The crux is the interpretation of the phrase 'in order' in deflationism's (3) - we must know P's meaning in order to know the truth-conditions of $P$. As I see it, (3) tells us that knowing $P$ 's meaning is a necessary condition for knowing the truth-conditions of $P-$ a condition that will be met with Combination, because knowing $P$ 's meaning and knowing $P$ 's truth-conditions amount to the same thing. I argued above that 'knowing $\mathrm{q}$ is sufficient for knowing p' does not imply 'we can come to know p by previously coming to know q'; similar examples demonstrate that 'knowing $\mathrm{p}$ is necessary for knowing q' does not imply 'we can come to know q only if 
we have previously come to know p'. So (3) does not imply (4). As Gupta and Dummett see it, knowledge of the meaning of a sentence comes first, and knowledge of what it is for that sentence to be true comes second, so that deflationists are committed to (4). But the Gupta/Dummett interpretation is not faithful to deflationism's essence.

Deflationism emphasizes that to attribute truth to a sentence is not to attribute any rich property to that sentence. Given the triviality of a truth attribution for deflationism, it is implausible that there is any real sense in which knowing a sentence's meaning precedes knowing its truth-condition. Certainly, given deflationism, one must know a sentence's meaning in order to know what it is for it be true, but it is difficult to give any credence to the idea that knowing the meaning of the sentence comes first, before knowing what it is for it be true. Take three contemporary contenders for a deflationary account of truth. On Brandom's anaphoric theory a truth attribution to 'snow is white' inherits its content from the quoted sentence, 'snow is white', just as a pronoun inherits its referent from its anaphoric antecedent. But we know the referent of a pronoun immediately upon knowing the referent of its anaphoric antecedent, and similarly, we know what it is for 'snow is white' to be true immediately on knowing the content of the sentence. On a disquotationalist view, to know that 'snow is white' is true is just to know that snow is white, while on a minimalist view, to know that 'snow is white' is true is to know that the proposition expressed by 'snow is white' is true, and that is just to know that snow is white. So for both disquotationalism and minimalism, on knowing what 'snow is white' means, we immediately know what it is for it to be true. Generally, on a deflationist view, it is implausible that one must already know the sense of a sentence in order to know its truth-condition (Dummett) or that our understanding of a sentence is prior to our understanding of its truth-condition (Gupta). Knowledge of the meaning of a sentence and knowledge of its truth-condition are too close on a deflationist view for there to be any temporal lapse or 
additional cognitive step to be taken between knowing the meaning of $P$ and knowing what it is for $P$ to be true. So Combination can hold that we come to know $P$ 's meaning and $P$ 's truth-condition simultaneously.

As a last point regarding Interpretive Chicken-and-Eggs, let me note that (3) implies (1). (3) tells us that I cannot know the truth-conditions of $P$ without knowing its meaning. But then if I know $P$ 's truth-conditions I must know its meaning, so knowing $P$ 's truth-conditions is sufficient for knowing its meaning. (3) and (1) alone do not generate Immiscibility.

Let me summarize my rejection of Interpretive Chicken-andEgg arguments. The Interpretive Chicken-and-Egg arguments say that Combination is circular because Davidsonians are committed to (2) and deflationists are committed to (4). However a Davidsonian theory of meaning is not committed to (2). While the Davidsonian theory is committed to (1) - knowing the truth-conditions of some sentence $P$ is sufficient for knowing $P$ 's meaning - this is because, in the right circumstances, knowing the truth-conditions of $P$ is knowing $P$ 's meaning. On the Davidsonian view, the path by which we might come to know $P$ 's meaning is laid out in the fictional history of the radical interpreter, who comes to know the truth-conditions of $P$ and $P$ 's meaning simultaneously. This position is available to the deflationist; while it is true, on a deflationist view, that one must know $P$ 's meaning in order to know the truth-conditions of $P$, this does not indicate that knowing $P$ 's meaning precedes knowing the truth-conditions of $P$.

\section{EXPLANATORY CHICKEN-AND-EGG ARGUMENTS}

From the perspective of the Interpretive Chicken-and-Egg arguments, the Davidsonian account should allow interpretation of sentences of L. The Explanatory Chicken-and-Egg arguments shift our attention from interpretation of $\mathrm{L}$ to the illumination of meaning promised by Davidsonians, holding that Combination mistakes the proper order in which we explain the ideas or concepts of meaning and truth. In this 
section, I show that the most convincing Explanatory Chicken-and-Egg arguments share a premise: If the notion of meaning is prior to the notion of truth, we cannot use the notion of truth to give an explanation of the notion of meaning. I reject this premise in section 7.

Early examples of the Explanatory Chicken-and-Egg in Gupta (1993) and Brandom (1994) are not convincing, because they do not make a clear distinction between meaning itself and the meanings of sentences. Gupta describes a "tension ... over two ways of reading the T-biconditionals: as elucidating the meanings of sentences and as elucidating 'true'. The two ways preclude each other" (1993, p. 68, my emphases) because the "former presupposes the concept of truth and uses the T-biconditionals to explain meaning; the latter presupposes meaning and uses the T-biconditionals to explain truth" (1993, p. 68, my emphases). Not so. On Gupta's two ways of reading the T-biconditionals, the former presupposes an understanding of 'true' (not the concept of truth) to elucidate meanings of sentences, and the latter presupposes meanings of sentences (not the concept of meaning) and uses the T-biconditionals to elucidate 'true'. ${ }^{16}$ Brandom is in a similar muddle, although he speaks of contents and contentfulness, rather than meanings and meaning (1994, p. 329). In these early arguments, the conclusions are framed for an Explanatory Chicken-and-Egg, so the premises should claim that Combination presupposes an understanding of the concept of meaning in order to explain the concept of truth, and presupposes an understanding of the concept of truth in order to explain the concept of meaning. But the actual premises, which are suitable for an Interpretive Chicken-and-Egg, claim that Combination presupposes an understanding of sentence meanings in order to understand the use of 'true', and an understanding of 'true' in order to understand sentence meanings. As a consequence, it is difficult to give a compelling reading of these arguments. ${ }^{17}$

Fortunately, Brandom (1997, 2002) offers a more clearly conceived Explanatory Chicken-and-Egg argument with reference to his own deflationary theory, the anaphoric theory, 
and Dummett (2003) and Collins (2002) with reference to deflationary theories more broadly. The arguments describe the immiscibility in terms of explanatory priority; the deflationist takes the notion of meaning to be prior to the notion of truth, the truth-conditional theory of meaning takes the notion of truth to be prior to the notion of meaning. The deflationist can explain truth, given the notion of meaning, and the truth-conditional semanticist can explain meaning, given the notion of truth; but neither can do both. But why not? An explanation of a notion, we gather, can employ only prior notions. So the crucial premise is this: If the notion of meaning is prior to the notion of truth, we cannot use the notion of truth to give an explanation of the notion of meaning.

First Brandom:

... I think that one cannot explain the notion of anaphora that is relied upon by broadly prosentential theories without appealing to an antecedent notion of propositional content - what in the simplest cases is inherited by a prosentence from its anaphoric antecedent. That is, one cannot entitle oneself to employ a notion of anaphora in one's semantic theory unless one is already entitled to use a notion of propositional content. Thus if one's explanation of 'true', and hence of truth conditions, is dependent upon a notion of anaphora, one cannot without circularity explain the notion of propositional contents in terms of truth or truth-conditions. For those notions cannot be made available for explanatory use in advance of an account of propositional content. (Brandom, 2002, p. 117) ${ }^{18}$

Brandom goes on to tell us that "orthodox disquotational accounts" are in the same boat as the anaphoric theory (2002, p. 117).

Now Dummett, using the term 'minimalism' loosely as a catch-all for a number of varieties of deflationism:

Minimalism conflicts with a truth-conditional theory of meaning because it assumes meaning as given antecedently to the notion of truth. This is most obvious for that version of minimalism which regards truth as primarily an attribute of propositions. Obviously, you cannot know what proposition a statement expresses unless you know what it means. What proposition is expressed by a statement depends upon that aspect of the statement's meaning that Frege called its 'sense' .... The notion of the meaning of a statement is thus prior to that of a proposition; and a minimalist of this variety is taking the notion of a proposition as prior to the 
notion of truth. But a truth-conditional theory of meaning explains meaning in terms of truth, and thus takes truth as prior to meaning. The two theories are thus irreconcilable. (Dummett, 2003, p. 22)

Finally, Collins:

Very roughly, deflationism seeks to explicate truth in terms of meaning, while the truth conditional conception of meaning seeks the converse, to explicate meaning in terms of truth. So, the explanations offered by the two conceptions apparently run in opposite directions and are thus incompatible. (2002, p. 497)

[A deflationist] seeks to account for truth via some notion of content or meaning, and it is this explanatory priority given to meaning which makes for deflationism's incompatibility with a truth based account of meaning. (2002, p. 508)

These authors do not agree on the exact nature of the circularity. For example, Dummett tells us that the circle arises because minimalists use the notion of a proposition to explain the notion of truth, and Davidsonians use the notion of truth to explain the notion of meaning, but that the notion of meaning is needed to explain the notion of a proposition. ${ }^{19}$ On the other hand Brandom tells us that the circle arises because anaphoric deflationists use the notion of anaphora to explain the notion of truth, and Davidsonians use the notion of truth to explain the notion of meaning (in Brandom's terms, propositional content), but that the notion of meaning (i.e., propositional content) is needed to explain the notion of anaphora. What all three authors share is their insistence that Combination cannot explain the notion of meaning in terms of truth if the notion of meaning is prior to that of truth; one assumes that this also motivates the mongrel Chicken-and-Egg arguments of Gupta (1993) and Brandom (1994). However, none of the arguments defend the shared premise by making clear why this explanatory structure is impossible. I reject this premise in objecting to Explanatory Chicken-and-Egg arguments. If my objection is successful, we need not dwell on the differences between Brandom, Collins, and Dummett. 


\section{WHY EXPLANATORY CHICKEN-AND-EGG ARGUMENTS} FAIL

More fully, the disputed premise says: If the notion of meaning is prior to the notion of truth, we cannot use the notion of truth to give an explanation of the notion of meaning. I take it that by 'notion', Brandom, Collins, and Dummett mean something like 'idea' or 'concept'. In my discussion, I will stick with the woolly term, 'notion', for fear of stacking the deck with a more precise term. The premise is an instance of the Priority Assumption:

If notion $\mathrm{A}$ is prior to notion $\mathrm{B}$, we cannot use notion $\mathrm{B}$ to give an explanation of notion $\mathrm{A}$.

The premise under attack gains its plausibility from the Priority Assumption, but while the Priority Assumption is apt in some circumstances, I will argue that it cannot be applied here.

My task is complicated by the absence of an explicit account of what it means to say that one notion is prior to another, since the aptness of the Priority Assumption rests both on the kind of explanation under consideration, and on what is meant by the priority of one notion to another. Take two examples. (These examples do not exhaust the options - there are other potential interpretations of 'explanation' and of 'notion $\mathrm{A}$ is prior to notion B'.) First suppose that an explanation of notion A that uses notion B should allow me to grasp notion A given my grasp of notion B (among other things, perhaps), and that to say that notion $\mathrm{A}$ is prior to notion $\mathrm{B}$ is to say that notion B cannot be grasped without a grasp of notion A. Then the Priority Assumption (that if notion A is prior to notion $\mathrm{B}$, we cannot use notion $\mathrm{B}$ to give an explanation of notion A) is justified. Second, suppose that an explanation of notion A that uses notion B should tell me what the relationship is between two already grasped notions $\mathrm{A}$ and $\mathrm{B}$, and that to say that notion $\mathrm{A}$ is prior to notion $\mathrm{B}$ is to say that in normal development, children grasp notion A before grasping notion $\mathrm{B}$. Then the Priority Assumption is 
not justified. In these examples, both kinds of explanation mentioned could be genuinely informative - the first by giving me a new notion that I did not already have (e.g., the notion of a cappuccino given my notion of an espresso), the second by revealing the connections between notions that I do have (e.g., the relationship between the notions of a square and of a right angle). In order to assess the aptness of the Priority Assumption for the case in hand, then, we must think both about the kind of explanation of meaning offered by the truth-conditional theory of meaning, and about the sense in which deflationism takes the notion of meaning to be prior to that of truth, and the truth-conditional theorist of meaning takes the notion of truth to be prior to that of meaning.

As evidence for the claim that deflationism takes the notion of meaning to be prior to that of truth, Brandom says that the notion of propositional content is prior to the notion of anaphora employed by prosententialism (2002, p. 117; 1997, pp. 147-148), Dummett tells us that the notion of meaning is prior to the notion of a proposition employed by minimalism (2003, p. 22), and Collins mentions the rôle of the truth from meaning principle "If $\mathrm{S}$ means that $\mathrm{p}$ in $\mathrm{L}$, then $S$ is true iff p" in both sentential and propositional deflationism (2002, p. 506). The deflationary theories are familiar to very few of those who are competent with the notion of truth. So the purported priority of meaning to truth is nothing to do with the order in which the notions are graspable, or the order in which they are normally grasped. In addition, we can safely rule out the idea that the notion of truth is a compound notion, composed of the notion of meaning and other notions there is no hint of this kind of construction in the evidence cited. Rather, the idea seems to be that a philosophical explanation of truth along these lines invokes the notion of meaning. Similarly, the purported priority of truth to meaning for the truth-conditional theorist of meaning has nothing to do with the order in which the notions are graspable, or the order in which they are normally grasped. Davidson's theories 
are familiar to very few of those who are competent with the notion of meaning, and in addition, Davidsonians make no pretence that their theory is an empirical theory of what is known by speakers of a language. Davidsonians give no hint that the notion of meaning is constructed from that of truth - quite the opposite - so we can rule out the idea that the notion of meaning is composed of the notion of truth and other notions. Again, the idea seems to be that a philosophical explanation of meaning along these lines invokes the notion of truth.

'Notion A is prior to notion B', in this context, means that notion $\mathrm{A}$ is invoked in the philosophical explanation of notion B. Cashing out the idea of priority, the Priority Assumption tells us that if notion $\mathrm{A}$ is invoked in the philosophical explanation of notion $\mathrm{B}$, we cannot use notion $\mathrm{B}$ to give an explanation of notion $\mathrm{A}$. While we now have a clear idea of what is meant by saying that notion $\mathrm{A}$ is prior to notion $\mathrm{B}$, the aptness of the assumption is still in question, because its aptness depends on the kind of explanation being given of notion A. The application of the Priority Assumption can be justified either by metaphysical or epistemological considerations about philosophical explanations. With metaphysical considerations, the justification rests on the relationship between the notions of $\mathrm{A}$ and $\mathrm{B}$. The relationship between the notions of $\mathrm{A}$ and $\mathrm{B}$ may be dictated by the relationship between the properties or objects or relations A and B - whatever the notion is a notion of - but of course this need not be the case, particularly where A and B are poorly understood. ${ }^{20}$ With epistemological considerations, the justification rests on the rôle that an explanation has for us in gaining an understanding of notion A. I will consider both metaphysical and epistemological justifications for the Priority Assumption.

In considering metaphysical justifications for the Priority Assumption, it will be helpful to follow Avramides (1989) in distinguishing reductive analyses from reciprocal analyses. A reductive (or new-level) analysis reveals that understanding of some concept $\mathrm{K}$ is to be achieved by understanding some other concepts $\mathrm{K}_{1}, \ldots, \mathrm{K}_{\mathrm{n}}$, where $\mathrm{K}_{1}, \ldots, \mathrm{K}_{\mathrm{n}}$ could replace $\mathrm{K}$ 
without residue. A reciprocal (or same-level) analysis tells us that understanding of a concept $\mathrm{K}$ is to be gained by discerning its place in a system of interrelated concepts $\mathrm{K}_{1}, \ldots, \mathrm{K}_{\mathrm{n}}{ }^{21}$ The reductive analyses attempt to break down concepts into simpler or more fundamental concepts, whereas the reciprocal analyses do not attempt to break down or decompose the target concept.

It is widely held that reductive analyses should be constrained along the lines suggested by the Priority Assumption for metaphysical reasons. ${ }^{22}$ David identifies in Kant the idea that "conceptual analysis is the mereology of concepts. The concept to be defined is a complex whole, and the defining concept should be the logical sum (or the logical product) of the constituent parts of the defined concept" (1993, p. 112). On the Kantian picture, circular analyses are ruled out. In a circular analysis, the analysandum appears in the analysans. But the analysandum must not appear in the analysans, because the things in the analysans should be parts of the analysandum, and the analysandum cannot be part of itself. ${ }^{23}$ Thus where reductive analyses are concerned there is a metaphysical argument for the Priority Assumption. However, this metaphysical argument has no force for reciprocal analyses. A reciprocal analysis does not propose to break down a complex concept into simpler parts, so the mereological reason to support the Priority Assumption for reductive analyses does not apply to reciprocal analyses. Further, the literature on circularity offers no other metaphysical reason to suppose that the Priority Assumption should apply to reciprocal analyses.

The metaphysical justification for the Priority Assumption will apply to our case if Davidson's truth-conditional theory of meaning is meant as a reductive analysis. But as Davidson has made perfectly clear, he does not offer a reductive analysis, he offers a reciprocal analysis, that enriches our understanding of meaning by outlining the connections between the concepts of truth and meaning, and other concepts. ${ }^{24}$ So there is no metaphysical justification for the Priority Assumption in this case. Now, deflationists might worry that the 
account of truth will not be truly deflationary if they have any truck with a reciprocal analysis. But the worry may be unfounded. The issue must turn on the role of truth in the reciprocal account. If truth's role in the reciprocal analysis is restricted to logical and expressive functions, as Kölbel and Williams argue, then perhaps there is no cause for concern.

It remains to be seen whether there is an epistemological motivation for the Priority Assumption. The epistemological motivation for the Priority Assumption may apply to either reductive or reciprocal analyses, but since Davidson's analysis is reciprocal we may limit our discussion appropriately. Humberstone gives a helpful summary of analytical circularity.

[The] usual way of explaining why circularity is a flaw in a putative analysis adverts to the role analysis is supposed to play for thinkers: if a concept is being explained, the explanation should not be one intelligible only to those already possessing the concept. This is just a formulation at the level of concepts of the usual grounds for objecting to circularity in the definition of terms: we are supposed to be explaining how the term defined is to be used in terms already familiar to one for whom the explanation is necessary. Analytical circularity is a fault, then, when and because it obstructs the transfer of understanding [which] an account of the application conditions of a concept may be designed to effect: from understanding of the terms in which the account is couched to understanding the concept being analysed. (Humberstone, 1997, p. 251)

So analytical circularity is an epistemic vice in an explanation if it blocks understanding of a target concept for a thinker who is not yet familiar with the target concept. If we conceive of the vice of circularity along these lines, we must look to the rôle that an explanation plays for thinkers in order to decide whether or not a circularity in the explanation is vicious. If the explanation is meant to function like a definition, providing an explanation of notion $\mathrm{A}$ to those who have no grasp of it, then the Priority Assumption applies - B cannot be used in the explanation of $\mathrm{A}$ if $\mathrm{A}$ is prior to $\mathrm{B}$. But the kind of explanation offered by a Davidsonian about meaning does not have this rôle. I have already pointed out that the notions of truth and meaning are familiar to those with no philosophical expertise; those of us with philosophical 
expertise are just as familiar with these notions. The explanation to be given of truth and meaning is not an explanation of notions that are completely alien to us, so it need not start from scratch. ${ }^{25}$ So this epistemological justification for the application of the Priority Assumption does not apply to our case. We have already seen that the metaphysical justification for the Priority Assumption does not apply, since Davidson's analysis is reciprocal rather than reductive. Thus there is no justification for applying the Priority Assumption to our case.

The reader may feel that I have neglected one reason for avoiding circularity in an account: The risk of triviality. But the neglect has no bearing on my conclusion, for two reasons. First, Combination is not trivial; even Collins' truth-from-meaning principle, however widely accepted, tells us something. ${ }^{26}$ Second, while some circular accounts are trivial, circularity is not in itself evidence of triviality. In support of this point, Blackburn (1993) offers an example of a false circular account of a response-dependent concept: " $\mathrm{X}$ is boring $\equiv$ we tend to be bored by $\mathrm{X}$ under normal conditions" (p. 261); Yablo (1993) offers an example of an informative circular definition: " $x$ is a number $={ }_{\mathrm{df}} x$ is zero or $x$ is some number's successor" (p. 150). A trivial account should be neither false nor informative, so circularity alone does not indicate triviality. ${ }^{27}$ If proponents of Immiscibility wish to argue that Combination is impossible for reasons of triviality, their argument cannot conclude by identifying a circularity in the combined account. More must be done to demonstrate that Combination is not only circular but also trivial. $^{28}$

To conclude, the Explanatory Chicken-and-Egg arguments have an instance of the Priority Assumption as a necessary premise: If the notion of meaning is prior to the notion of truth, we cannot use the notion of truth to explain the notion of meaning. The Priority Assumption is entirely appropriate for metaphysical reasons with regard to reductive analyses. But we are concerned with reciprocal analyses, where the assumption is appropriate only when the analysis or explanation is meant 
to play the epistemic rôle of making familiar an unknown concept. The Davidsonian and deflationary explanations are not like that - we already know something about truth and meaning, and the epistemic rôle of the explanations is to deepen our acquaintance. Thus the Explanatory Chicken-and-Egg arguments fail.

\section{CONCLUSION}

I have rejected the circularity arguments for Immiscibility. However, proponents of Immiscibility have other arguments, the modal confusion and explanatory inadequacy arguments, in their arsenal. At least some of these arguments will be less easily dismissed. ${ }^{29}$

\section{NOTES}

1 See also Lepore and Ludwig (2003) and Ludwig (2003) who argue that truth-theoretic semantics can be conducted regardless of the nature of truth, and Williams (2004).

2 Williams (1999) and Kölbel $(2001,2002)$ reject explanatory inadequacy arguments because they think truth has an expressive but not an explanatory role in the truth-conditional theory of meaning. But see Bar-On et al. (2000).

3 Some modal confusion arguments hold that the deflationist's T-sentences are necessary, the truth-conditional theorist's T-sentences contingent, others that the truth-conditional theorist's T-sentences are empirical, whereas the deflationist's are not.

4 For discussion see Dummett (1975, 1976), McDowell (1980) and Avramides (1989). For my purposes, we may skip over the details of the argument for the theory-building approach, of Davidson's argument that a truth theory can serve as part of a meaning theory, and of the method by which a T-theorem must be derived in order for it to be interpretive. Accessible accounts may be found in Lepore and Ludwig (2003) and Platts (1997).

5 Here I follow Ludwig (2002) and Lepore and Ludwig (2003) in distinguishing a truth theory for $\mathrm{L}$ from a meaning theory for $\mathrm{L}$.

6 This is a much disputed claim. See Davidson (1973), and numerous further discussions, e.g., Higginbotham (1991), Segal (1999), Rumfitt (2001), Kölbel (2001), Lepore and Ludwig (2005). 
7 See, for example, Davidson (1973) p. 137, Foster (1976) pp. 6-7, McDowell (1980) p. 117, Dummett (1993) p. 13, Ludwig (2003) pp. 2627, Lepore and Ludwig (2003) pp. 52, 54.

8 The metaphor of illumination, and exactly how illumination is to be achieved, remain frustratingly obscure. Lepore and Ludwig (2005) summarize the idea more tidily than most, emphasizing the illumination of the concept of meaning. In doing so, they tidy up Davidson's presentation; he sometimes speaks of illumination of the concept of meaning, sometimes of the illumination of meaning, seemingly drawing no distinction between the two.

9 Dummett could not have had Davidson in mind when he first published this passage, but nevertheless this argument inspires all other arguments for Immiscibility.

10 Patterson (2005) argues that Dummett's argument does not show even this much. However, Patterson takes it that Dummett means to show Incompatibility, whereas I assume that he means to show Immiscibility but not Incompatibility.

11 For Dummett (2002), disquotationalists fall in the category of s-level theorists, minimalists and weak deflationists such as McGrath (1997) fall in the category of p-level theorists. S-level theorists take the predicate 'is true' to apply to linguistic items (sentences or statements), $\mathrm{p}$-level theorists take the predicate 'is true' to apply to propositions. I use the more familiar terminology in my exegesis, even though this does a mild injustice to Dummett's categories. See Dummett pp. 249-250.

12 All the versions of deflationism in question are committed to the principle of semantic shift - a principle allowing semantic ascent and descent between used declarative sentences on the one hand and truth ascriptions to mentioned sentences or propositions on the other. Instances include, for example, "The statement "Snow is white" is true if and only if snow is white' and 'The proposition that snow is white is true if and only if snow is white'. In Dummett's terminology, minimalism is any theory holding the theses "(1) that every instance - or almost every instance - of the principle of semantic shift, either as applied to statements or as applied to propositions, holds good; and (2) that by stipulating that all those instances hold good, we give the whole explanation of the meaning of the word 'true'." (Dummett, 2003, p. 22) In this paper, I use the term 'minimalism' with the restricted sense stipulated in section 2 .

13 The 1999 argument (pp. 276-277) closely follows the pattern of the 1959 argument. Dummett (2002) tells us that the disquotational notion of truth "cannot serve to explain the meanings possessed by sentences of the language such as "Venus has no satellites" because disquotational truth "presupposes a prior grasp of their meanings" (2002, p. 256), and that the minimalist theory takes "the propositions to which truth is to be ascribed, or of which it is to be denied, as given" (2002, p. 252). He emphasizes 
that by the latter he does not mean that a minimalist theory "presupposes a philosophical account or defence of the general notion of propositions: it presupposes only that we can know what proposition is expressed by a given utterance" (2002, p. 252). Dummett (2003) tells us "the [deflationist] takes as given the meanings of English statements" (2003, p. 24).

14 Both Dummett's and Gupta's Chicken-and-Egg arguments leave implicit the contrast with substantivism. The contrast would have to made explicit to show that the combination of deflationism and the truth-conditional theory of meaning has a distinctive flaw, i.e., a flaw not shared by the combination of substantivism and the truth-conditional theory of meaning.

15 This position comes under attack from more empirically-minded philosophers. For discussion see, among others, Antony (1997) and Rumfitt (2001).

16 It is the muddling of sentence meanings and meaning, rather than of 'true' and truth, that makes the argument a mongrel Chicken-and-Egg; on at least some deflationary views, an understanding of 'true' constitutes an understanding of truth, so Gupta's slide between understanding 'true' and understanding truth is acceptable.

17 The shortest bridge between the proffered premises and the proposed conclusion that I have found involves four additional premises, two of them extremely difficult to defend. Cf. note 16 .

18 Brandom continues: "For they evidently take for granted the meanings of the sentences that are the results of disquotation" (2002, p. 117). We are now in a position to see, though, that this is an Interpretive Chicken-and-Egg premise, unsuitable for establishing an Explanatory Chicken-and-Egg conclusion.

19 We should not take literally Dummett's occasional mention in Explanatory Chicken-and-Eggs of truth being prior to meaning, or meaning being prior to truth. As his premises make clear, what he means is that the notion of truth is prior to the notion of meaning, or the notion of meaning prior to the notion of truth.

20 Where scientific, as opposed to philosophical, explanations are concerned, a desire for an explanation in terms of the most basic objects or properties might lead us to demand that the objects or properties that are invoked in the explanans be more fundamental than those that are to be explained. Then a variant of the Priority Assumption would apply to scientific explanations: if $\mathrm{A}$ is more fundamental than $\mathrm{B}$, we cannot use $\mathrm{B}$ to give an explanation of A. But there is no reason to suppose that A's being more fundamental than $\mathrm{B}$ will guarantee that the notion of $\mathrm{A}$ is more basic than the notion of $\mathrm{B}$.

21 See Avramides (1989), pp. 19-26

22 Widely, but not universally, held; but if reductive analyses may be circular, then so much the better for my position. For discussion see 
Johnston (1989), particularly pp. 147-148, Blackburn (1993), David (1993), Belnap (1993), Yablo (1993), Orilia (2000) and King (2000).

23 For a tidy summary, see Humberstone (1997, p. 251).

24 Davidson (1990) emphasizes that his account of meaning is reciprocal, not reductive (see pp. 314-315); Davidson (1996) emphasizes that his account of truth is reciprocal, not reductive (see p. 278).

25 It might be desirable if the theory could explain the illuminated concepts to someone who had no grasp of them; but the fact that it cannot does not vitiate the theory's explanatory function.

26 The principle seems obvious to us because it has become well-entrenched since Frege first commented on the connection between truth and meaning, not because it is trivial.

27 See in addition Johnston (1989) and Holton (1991).

28 See also Gupta and Belnap (1993) and Yablo (1993) on circular definitions.

29 Thanks to Jon Kvanvig, Peter Markie, Matthew McGrath, Andrew Melnyk, an audience at the University of Minnesota Twin Cities and anonymous referees for discussion and/or comments. This paper supersedes earlier papers on the same topic; thanks to Louise Antony, Dorit Bar-On, Simon Blackburn, Hartry Field, Bill Lycan, and Keith Simmons for comments on those papers, and also to audiences at the American Philosophical Association, the Joint Session of the Aristotelian Society and the Mind Association, the North and South Carolina Philosophical Societies, the University of Missouri at Columbia and at St. Louis, Union College, and the University of North Carolina at Chapel Hill. My argument has been shaped by a broader literature on circularity, particularly Humberstone (1997). Work on the paper was completed with a grant from the University of Missouri Research Board.

\section{REFERENCES}

Antony, L. (1997): Meaning and Semantic Knowledge, Proceedings of The Aristotelian Society 71(Suppl), 177-208.

Avramides, A. (1989): Meaning and Mind, Cambridge, MA: The MIT Press. Bar-On, D., Horisk, C. and Lycan, W.G. (2000): Deflationism, Meaning and Truth-Conditions, Philosophical Studies 101, 1-28.

Belnap, N. (1993): On Rigorous Definitions, Philosophical Studies 72, 115146.

Blackburn, S. (1993): Circles, Finks, Smells and Biconditionals, Philosophical Perspectives 7, 259-279.

Brandom, R.B. (1994): Making it Explicit: Reasoning, Representing, and Discursive Commitment, Cambridge, MA: Harvard University Press.

Brandom, R.B. (1997): 'From Truth to Semantics: A Path through Making 
it Explicit', in E. Villanueva (ed.), Truth, Philosophical Issues, Vol. 8, pp. 141-154.

Brandom, R.B. (2002): Explanatory vs. Expressive Deflationism About Truth, in R. Schantz (ed.), What is Truth?, Berlin and New York: Walter de Gruyter.

Collins, J. (2002): Truth or Meaning? A Question of Priority, Philosophy and Phenomenological Research 65, 497-536.

David, M. (1993): Introduction, Philosophical Studies 72, 111-114.

David, M. (1994): Correspondence and Disquotation, Oxford: Oxford University Press.

Davidson, D. (1973) Radical Interpretation, Dialectica 27, 313-328. Page references to a reprint in D. Davidson (1984) Inquiries into Truth and Interpretation. Oxford: Oxford University Press.

Davidson, D. (1990): The Structure and Content of Truth, Journal of Philosophy 87, 279-328.

Davidson, D. (1996): On the Folly of Trying to Define Truth, Journal of Philosophy 93, 263-278.

Dummett, M. (1959): Truth, Proceedings of the Aristotelian Society 59, 141162. Page references to a reprint in M. Dummett (1978) Truth and Other Enigmas. Cambridge, MA: Harvard University Press.

Dummett, M. (1975): 'What is a theory of meaning?', in S. Guttenplan (ed.), Mind and Language. Oxford: Oxford University Press. Page references to a reprint in M. Dummett (1993) The Seas of Language. Oxford: Oxford University Press.

Dummett, M. (1976): What is a theory of meaning? (II), in G. Evans and J. McDowell (eds.), Truth and Meaning: Essays in Semantics, Oxford: Oxford University Press.

Dummett, M. (1993): The Logical Basis of Metaphysics, Cambridge, MA: Harvard University Press.

Dummett, M. (1999): Of What Kind of Thing is Truth a Property?, in S. Blackburn and K. Simmons (eds.), Truth, Oxford: Oxford University Press.

Dummett, M. (2002): The Two Faces of the Concept of Truth, in R. Schantz (ed.), What is Truth?, Berlin and New York: Walter de Gruyter.

Dummett, M. (2003): The Dewey Lectures: Truth and the Past. Lecture 1: The Concept of Truth, Journal of Philosophy 100, 5-25.

Etchemendy, J. (1988): Tarski on Truth and Logical Consequence, Journal of Symbolic Logic 53, 51-79.

Field, H. (1994): Deflationist Views of Meaning and Content, Mind 103, 249-285.

Foster, J.A. (1976): Meaning and Truth Theory, in G. Evans and J. McDowell (eds.), Truth and Meaning: Essays in Semantics, Oxford: Oxford University Press. 
Grover, D., Camp, J. and Belnap, N. (1975): A Prosentential Theory of Truth, Philosophical Studies 27, 73-125.

Gupta, A. (1993): A Critique of Deflationism, Philosophical Topics 21, 5781.

Gupta, A. and Belnap, N. (1993): The Revision Theory of Truth, Cambridge, MA: The MIT Press.

Higginbotham, J. (1991): Truth and Understanding, Iyyun, the Jerusalem Philosophical Quarterly 40, 271-288.

Holton, R. (1991): Intentions, Response-Dependence, and Immunity from Error, in P. Menzies (ed.), Response Dependent Concepts, Canberra: ANU Working Papers in Philosophy.

Horwich, P. (1998): Truth, 2nd ed. Oxford: Oxford University Press.

Humberstone, I.L. (1997): Two Types of Circularity, Philosophy and Phenomenological Research 57, 249-280.

Johnston, M. (1989): Dispositional Theories of Value, Proceedings of the Aristotelian Society Supp. Vol. 63, 139-174.

King, J.C. (2000): On the Possibility of Correct Apparently Circular Dispositional Analyses, Philosophical Studies 98, 257-278.

Kölbel, M. (2001): Two Dogmas of Davidsonian Semantics, Journal of Philosophy 98, 613-35.

Kölbel, M (2002): Truth without Objectivity, London and New York: Routledge.

Lance, M. (1997): 'The Significance of Anaphoric Theories of Truth and Reference', in E. Villanueva (ed.), Truth, Philosophical Issues, Vol. 8, pp. 181-198.

Leeds, S. (1978): Theories of Reference and Truth, Erkenntnis 13, 111-129.

Lepore, E. and Ludwig, K. (2003): Truth and Meaning, in K. Ludwig (ed.), Donald Davidson, Cambridge: Cambridge University Press.

Lepore, E. and Ludwig, K. (2005): Donald Davidson: Meaning, Truth, Language, and Reality, New York: Oxford University Press.

Ludwig, K. (2002): What is the role of a truth theory in a meaning theory?, in J.K. Campbell, M. O'Rourke and D. Shier (eds.), Meaning and Truth: Investigations in Philosophical Semantics, New York and London: Seven Bridges Press.

Ludwig, K. (2003): Introduction, in K. Ludwig (ed.), Donald Davidson, Cambridge: Cambridge University Press.

McDowell, J. (1980): Meaning, communication, and knowledge, in Z. van Straaten (ed.), Philosophical Subjects, Oxford: Oxford University Press.

McGrath, M. (1997): Weak Deflationism, Mind 106, 69-98.

Orilia, F. (2000): Meaning and Circular Definitions, Journal of Philosophical Logic 29, 155-169.

Patterson, D. (2005): Deflationism and the Truth Conditional Theory of Meaning, Philosophical Studies 124, 271-294. 
Platts, M. (1997): Ways of Meaning, 2nd ed. Cambridge, MA: The MIT Press.

Quine, W.V.O. (1970): Philosophy of Logic, Englewood Cliffs, NJ: Prentice Hall.

Ramsey, F.P. (1931): On Facts and Propositions, in R.B. Braithwaite (ed.), The Foundations of Mathematics. London: Paul, Trench, Trubner. Page references to a reprint in S. Blackburn and K. Simmons (eds.), Truth. Oxford: Oxford University Press.

Resnik, M. (1990): Immanent Truth, Mind 99, 405-424.

Rumfitt, I. (1995): Truth-Conditions and Communication, Mind 104, 827862.

Rumfitt, I. (2001): Semantic Theory and Necessary Truth, Synthese 126, 283-324.

Segal, G. (1999): How a Truth Theory can do Duty as a Meaning Theory, in U. Zeglen (ed.), Donald Davidson: Truth, Meaning and Knowledge, London and New York: Routledge.

Soames, S. (1984): What is a Theory of Truth?, Journal of Philosophy 81, 411-29.

Soames, S. (1997): 'The Truth about Deflationism', in E. Villanueva (ed.), Truth, Philosophical Issues, Vol. 8, pp. 1-44.

Soames, S. (1999): Understanding Truth, Oxford: Oxford University Press.

Williams, M. (1999): Meaning and Deflationary Truth, Journal of Philosophy 96, 545-64.

Williams, M. (2004): Context, Meaning, and Truth, Philosophical Studies 117, 107-129.

Yablo, S. (1993): Definitions, Consistent and Inconsistent, Philosophical Studies 72, 147-175.

Department of Philosophy

438 General Classroom Building

University of Missouri

Columbia, MO 65211-4160

USA

E-mail:horiskc@missouri.edu 